\title{
Building Excitement, Experience and Expertise in Computational Science among Middle and High School Students
}

\author{
Patricia Jacobs \\ Shodor SUCCEED Apprenticeship Program \\ \{patricia.jacobs\}@shodor.org \\ http://www.shodor.org/succeed/apprenticeships
}

\begin{abstract}
Three of the most important skills for advancing modern mathematics and science are quantitative reasoning, computational thinking, and multi-scale modeling. The SUCCEED Apprenticeship program gives students the opportunity of exploring all three of these areas. The SUCCEED Apprenticeship program uses innovative approaches to get students excited about computational science. The overall goal of this program is to provide middle and high school students with authentic experiences in the techniques and tools of information technology with a particular focus on computational science. The program combines appropriate structure (classroom-style training and project-based work experience) with meaningful work content, giving students a wide variety of technical and communication skills. The program provides middle and high students from ethnically and economically diverse backgrounds with training and authentic experiences in using computational science.
\end{abstract}

Keywords: Computational Science, Math, Science, Technology, Engineering, Modeling, Interactive.

\section{Introduction}

Shodor, a national resource for computational science in Durham, N.C. is dedicated to the improvement of science and mathematics education by promoting the effective use of computer modeling and simulation technologies. The SUCCEED Apprenticeship program is one of a wide range of programs provided by Shodor. The overall goal of the SUCCEED Apprenticeship program is to provide activities and support mechanisms, and mentoring to move students from an excitement for computational science and Information Technology (IT) to becoming an expert in one or more areas of computational science and associated IT components

The SUCCEED Apprenticeship program provides students with authentic and appropriate experiences in the use of computational science and advanced technologies and techniques to study scientific events within the context of science, mathematics and engineering and to produce evidence that students become proficient in these skills. In addition to the computational and technical skills,

G. Allen et al. (Eds.): ICCS 2009, Part II, LNCS 5545, pp. 15-24, 2009.

(C) Springer-Verlag Berlin Heidelberg 2009 
the program also enable student apprentices to acquire a set of problem solving, collaboration and communication skills identified as valuable for 21 st century workforce.

Significant work has proceeded during the program to develop and evaluate the project methodology of bridging the excitement-expert gap opportunities for upper middle and high school students in the local area.

\section{Program Overview}

The SUCCEED Apprenticeship program, which began in January 2006, builds on Shodors SUCCEED (Stimulating Understanding of Computational science through Collaboration, Exploration, Experiment and Discovery) program which provides workshops to introduce middle and high school students to technologies, techniques and tools of computational science. Once students have shown that excitement for math and science, they have the opportunity to participate in the SUCCEED Apprenticeship program. This program allows upper middle and high school students to work with Shodor staff and other scientists in a learning or apprentice mode. Apprentices use computational science to conduct scientific research, create mathematical models of scientific phenomenon and use those models to perform a variety of science and mathematical experiments.

The SUCCEED Apprenticeship program is targeted towards developing and evaluating activities and support mechanisms to move students from an excitement for computational science and IT, to becoming an expert in one or more areas of computational science and associated IT components. The project looks to primarily answer the question: what programs, activities, and support mechanisms are required to ensure that excited students become expert students in one or more areas, and how is that transition evaluated? The project methodology looks to bridge the excitement-expert gap by providing long-term, mentor-supported opportunities for upper middle and high school students in the local area.

During their participation in the program, apprentices take classes, work in project teams on local, regional and nationally funded projects, and have numerous opportunities to develop experience, culminating in the development of expertise in one or more areas of computational science. For example, apprentices may work in the field of computational chemistry, helping support Shodor's statewide computational chemistry computing services.

Through the combination of appropriate structure and meaningful work content, the SUCCEED Apprenticeship Program provides outstanding opportunities for students while providing the project staff with the mechanism by which to measure and evaluate this pipeline-building program.

\section{Participants}

The SUCCEED Apprenticeship Program, in its third year, has already surpassed its goal of working with 100 students over a three-year period. Participants are 
upper middle and rising 9th-12th grade students who have an interest in science, technology, engineering and mathematics (STEM). Each apprentice is required to spend 780 hours in the program over the course of two years. Apprentices are recruited from Shodor SUCCEED workshops, local school-based programs and summer camp programs. Students are interviewed and admitted based on their interest in computational science, IT and STEM areas. Apprentices are paid a stipend over the course of their apprenticeships, which could be extended as long as two years.

During the Fall of 2007, the SUCCEED Apprenticeship program had approximately 60 applicants, twice as many applicants as we had space available for in the 2007-2008 class. Applicants were from diverse ethnic and socio-economic backgrounds. Each applicant completed an online application for consideration in the program. Each student was interviewed and evaluated in the following areas: their interest in the program, commitment to the program, teamwork, communication (both oral and written), and leadership.

After careful review of each applicant's application, and based on the comments from staff during the interviews, the program enrolled 50 new apprentices (beginner apprentices) for the 2007-2008 school year.

The new enrollment increased the total number of beginner and advanced apprentices enrolled in the SUCCEED Apprenticeship program for 2007-2008 school year to 71 .

\section{Program Structure and Curriculum}

During the second and third year of the program, we continued to develop and evaluate the SUCCEED Apprenticeship program methodology. Apprentices were divided into cohort 1 (beginner apprentices) and cohort 2 (advanced apprentices) which depends on when they enrolled in the program. Due to the success and the number of students enrolled in the SUCCEED Apprenticeship program, the program has divided the students into different tracks (Track A and Track B). Students attend workshops depending on the Track in which they selected. Track A classes were held on the 1st and 3rd Saturday of each month, while Track B classes were held on the 2nd and 4th Saturdays each month. Both the advanced and beginner apprentices were divided into Tracks. Thus, classes were held every Saturday at Shodor for the beginner and advanced apprentices. The Track schedule allowed us to accommodate the large number of students in the program and to provide flexibility to the students.

Students in their second year of the program worked on different projects for local organizations. These projects challenged the knowledge of the apprentices and allowed them to work with real clients in the community. The first year apprentices completed and presented mini-projects on modeling, web design and other uses of innovative technology. In addition, some apprentices became apprenterns or completed the program to become interns at Shodor.

Throughout the year, all apprentices additionally improve math skills using computational tools; improve writing skills by completing weekly journals to 


\begin{tabular}{|c|c|c|}
\hline & $\underline{\text { School Year }}$ & Summer \\
\hline $\begin{array}{l}\text { Time } \\
\text { commitment }\end{array}$ & - 18 hours per month & - 6 weeks, full-time \\
\hline $\begin{array}{l}\text { All Students } \\
\text { Must }\end{array}$ & $\begin{array}{l}\text { - attend Saturday workshops } \\
\text { twice a month to learn new } \\
\text { computational science and STEM } \\
\text { skills } \\
\text { - spend additional time working in } \\
\text { the office on projects }\end{array}$ & $\begin{array}{l}\text { - attend career days } \\
\text { and team building } \\
\text { activities }\end{array}$ \\
\hline $\begin{array}{l}\text { Beginners } \\
\text { (first year) }\end{array}$ & $\begin{array}{l}\text { - attend workshops on basic IT } \\
\text { skills: agent modeling, web } \\
\text { design, programming, graphics } \\
\text { - two-month subject modules } \\
\text { culminating in creative group } \\
\text { projects }\end{array}$ & $\begin{array}{l}\text { - attend classes in } \\
\text { math, journaling, } \\
\text { problem solving, } \\
\text { creative thinking } \\
\text { - help Shodor staff on } \\
\text { STEM projects }\end{array}$ \\
\hline $\begin{array}{l}\text { Advanced } \\
\text { (second year) }\end{array}$ & $\begin{array}{l}\text { - teams begin projects for actual } \\
\text { clients: mentored by a Shodor } \\
\text { staff members } \\
\text { - workshops on software } \\
\text { development process, high level } \\
\text { design, detailed design, } \\
\text { database/ER diagrams, user } \\
\text { interface, and testing }\end{array}$ & $\begin{array}{l}\text { - work on and } \\
\text { complete client } \\
\text { projects } \\
\text { - projects must pass a } \\
\text { quality assurance } \\
\text { process of verification } \\
\text { and validation }\end{array}$ \\
\hline
\end{tabular}

Fig. 1. SUCCEED Apprenticeship Program Structure

reflect on what they have learned and improve communication skills through regular discussions with their mentor and through oral presentation.

\section{Program Activities and Findings}

There are five major complementary and interdependent activities of the SUCCEED Apprenticeship program:

1. Teaching and supporting the appropriate and authentic use of IT-related technologies, techniques, and tools, with a particular focus on computational science and its associated areas.

Apprentices attended workshops to gain experience and develop expertise in one or more areas of computational science and associated uses of the technologies, techniques, and tools of IT, within the context of stem. Students were introduced to computational science through a two-week (60-hour), academically intensive education and research program. Students learned and used advanced computational science technologies, techniques, and tools to study a wide variety of scientific events. Topics involved general uses of computational science, basic numerical methods, scientific programming, model validation and verification and research methods incorporating computational science.

Throughout the 2007-2008 school year, the apprentices attended workshops, completed assignments and worked on group projects. Each apprentice had a time commitment of 18 hours a month at Shodor during the school year and 240 hours during the summer. The 18 hours a month consist of 2 classes and 2 hours a week in the afternoons. The apprentices attended workshops every other Saturday to learn new computational science and STEM skills. Outside of class, they were given assignments to practice and use new skills and group projects to demonstrate the knowledge of a given skill set. 
Apprentices new to the program, beginner apprentices, had a more structured curriculum. Beginning apprentices attended classes in basic IT skills such as agent modeling, web design, programming and graphics. Their work was organized into modules of two to three month durations. After a module was completed, apprentices worked in teams to complete assigned projects. During the summer, the beginner apprentices attended classes in math, journaling, problem solving and creative thinking, held career days and team building activities.

Advanced apprentices (students in their 2nd year of the program) focused on a project based curriculum. All advanced apprentices were assigned to a team to work with mentors and clients on projects and to receive training as needed. Advanced apprentices learned advanced modeling, software development processes, high level design, detailed design, database/ER diagrams, graphics and quality assurance.

During Fall 2007, the Apprenticeship program added a new component, the Apprenticeship Math Component (AMC), to help students continue to improve their math skills. The AMC leverages the math resources in Shodor's award winning Interactivate courseware. Students are required to complete an associated set of activities in Number/Operations, Geometry/Measurement, Algebra and Probability/Statistics that are graded according to a rubric specific to the topic. Additionally, students are asked to write about the mathematics in the activity and assess the associated materials. Students are required to correct their work until it meets a particular score valued from the rubric.

All apprentices are required to re-work all of their assignments and projects until the quality of their work meet the rubrics or standards set by the staff and mentors. Once apprentices meet the requirements for class attendance, assignments and projects they receive a stipend. Stipend deadlines are set for four times throughout the year.

2. Provide mentors to define individual goals and timelines, and provide guidance through technical difficulties. Mentors monitor work progress as well as skill development for individual interns. In addition, mentors are responsible for overall research team dynamics, distribution of work and project oversight.

In addition to students attending classes, the SUCCEED Apprenticeship program continues to focus on mentoring students. The SUCCEED Apprenticeship program seeks to implement a 'true' apprenticeship program where young people learn from working with and learning from those with more experience. Shodor has approximately 18 staff who have a range of expertise in computational physics, biology, chemistry, math as well as computer science, system administration, graphics and web design. Each staff is assigned to mentor 6-7 students. Students are required to meet one hour per month with their mentor. Communication between mentors, program coordinator and parents is also on-going throughout the program.

In addition to monthly meetings, mentors track progress and skill development of apprentices by reviewing the apprentices weekly reflections (questions students have to answer weekly), progress on individual assignments and projects. 
Many students receive additional mentoring from staff when they need help understanding and/or completing out of class assignments and projects. Staff also mentor and provide leadership for the advanced apprentices as they work in research teams on their projects. Staff help facilitate project plans, design and set up meetings with project clients.

3. Provide opportunities for apprentices to work on local, regional and nationally funded projects. The projects are done as a learning process, and thus will require intensive guidance to ensure quality workmanship.

Throughout the program, apprentices are provided with the opportunity to work on local, regional and nationally funded projects. During Fall 2007 and Spring 2008, we continued to partner with local organizations to provide real world experience for our advanced apprentices' projects. These projects range from working with with local organizations to learning and developing skills for Shodor's award winning resources such as CSERD (www.shodor.org/refdesk) and Interactivate projects (www.shodor.org/interactivate).

4. Providing instruction and opportunities to practice a wide variety of communication skills, including working effectively in a group, interacting with customers and clients, teaching younger students about the technologies and exercising leadership.

The SUCCEED Apprenticeship program provides opportunities for apprentices to practice a wide variety of communication skills, including working effectively in a group, interacting with clients as well as teaching STEM workshops for younger students. During 2007-2008, apprentices had to prepare presentations and present several projects they worked on to demonstrate their knowledge of the skills they learned. The presentations helped the apprentices improve their communication skills.

Apprentices were also given the opportunity to teach workshops about computational science technologies and tools to younger students at Shodor workshops. Apprentices taught workshops from system and agent modeling to system administration to middle and high school students.

5. Providing formal and informal opportunities in critical thinking, including data retrieval, data organization and analysis, application of evidence-based reasoning, problem-solving, creative thinking and decision making.

The SUCCEED Apprenticeship provides many opportunities for apprentices to use and demonstrate critical thinking skills. Apprentices must attend classes to learn computational science and STEM skills every other Saturday. Apprentices were given assignments to practice and use new skills. In addition, apprentices completed group projects to demonstrate a given skill set. Advanced apprentices worked in project teams to integrate various technical skills needed for the completion of their projects. These projects required that the apprentice use a variety of innovative skills as well as problem solving. Advanced apprentices learned and used skills such as modeling, PHP, MySQL, CSS, HTML, Javascript and Googlemap for their projects. 


\section{Evaluation}

An extensive evaluation of the value added and the measurability of the Apprenticeship program is assessing the extent to which the appropriate structure and meaningful work content effectively develops students to become an expert in the areas of computational science and associated IT components. For 20072008, the SUCCEED Apprenticeship program had an overwhelming number of applicants for the program. For Fall 2007, we had a total number of 71 students enrolled in the program. We continued to evaluate the program's success and to improve the effectiveness of the program's structure and curriculum. Evaluation data combines students' participation, completion of assignments, journals, responses to routine surveys, as well as feedback from staff and others involved in the program.

In addition to working on their assignments and projects, apprentices are required to complete a web portfolio that displays their skills and knowledge learned at Shodor. Since the program began in 2005, an extensive evaluation process has helped us continually improve the effectiveness of the program's structure and curriculum. Not only have applications increased over the past three years, the percentage of students who stay with the program has nearly doubled. With the first group of program graduates, we see that these apprenticeships have been successful in maintaining apprentices' interest in science, math and technology as shown by their completion of the program and their career plans.

Goal 1: To build and maintain excitement for math and science in a diverse demographic of middle and high school students. The data presented below in Figure 2 show that the program has continued to attract and retain a diverse demographic of middle school students. Advanced Apprentices: In Fall 2007, 29 apprentices remained in the program through the summer of 2007. Twenty of these apprentices, then in their second year, returned for fall 2007. Four of these were accepted as Shodor Interns. Of those who returned the breakdown by gender and ethnicity was as follows: Female: 35\%; African-American: $26 \%$; Other Minorities: 26\%. The largest subgroups were White Males and Minority Females. In addition, 14 apprentices continued in the program through Summer

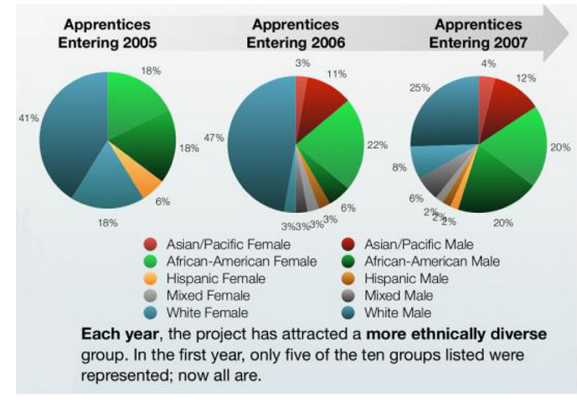

Fig. 2. SUCCEED Apprenticeship Demographics 


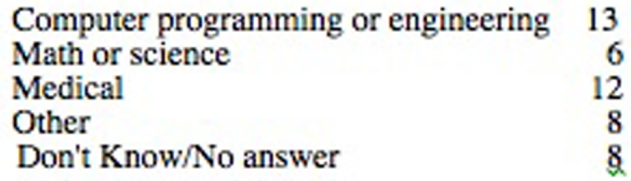

Fig. 3. Apprentices Interest in STEM areas

of 2008 and completed advanced IT projects as described in a later section of this report. The breakdown by gender and ethnicity of this population was as follows: Female: $43 \%$; Minority: $64 \%$.

In a addition, to a diverse group of students, the SUCCEED Apprenticeship program also seeks to increase or maintain student's excitement for STEM. We have taken persistence in intention to pursue a career in STEM or a STEMrelated career. as an indicator of excitement for STEM. Soon after being recruited in Fall 2007 beginning apprentices responded to a questionnaire that asked, among other items, to indicate their career goals.

GOAL 2. To enable student apprentices to acquire a set of technical, problem solving, collaboration and communication skills identified as valuable for the IT-intensive workplace.

This goal encompasses both computational science and technical (IT) skills and workplace (SCANS) skills which were assessed separately as follows.

Basic Skill Level - Technical Skills

The structure of the program, developed over the past three years, provides preliminary instruction followed by hands-on experience for all apprentices during the first year of the apprenticeship. At the end of the first year mentors rated beginning apprentices on a 1-5 scale on ability at the basic level to use the skills that had been taught. Mentors ratings are listed below as High(4 -5), Medium (3.0-3.9), Low (1-2.9).

\section{Number of Apprentices at Each Level of Proficiency Cohort 3, Year 1}

\begin{tabular}{|l|r|r|r|r|}
\hline N=35 & High & Med) & Low & $\begin{array}{l}\text { No } \\
\text { Rating }\end{array}$ \\
\hline JAVA & 23 & 4 & 4 & 4 \\
\hline Source & & & & \\
Control & 20 & 7 & 4 & 4 \\
\hline UNIX & 12 & 9 & 11 & 0 \\
\hline HTML/CSS & 14 & 17 & 4 & 0 \\
\hline Graphics & 6 & 28 & 1 & 0 \\
\hline PHP & 0 & 35 & 0 & 0 \\
\hline NetLogo & 24 & 5 & 2 & 5 \\
\hline EXCEL & 19 & 5 & 3 & 8 \\
\hline
\end{tabular}

Some apprentices have become more proficient than others but it is important to note that all have been introduced to these computer programs; those apprentices who are retained in the program will continue to improve these skills.

Fig. 4. Basic Skill Level 


Number of Apprentices at Each Level of Proficiency
\begin{tabular}{|l|r|r|r|r|}
\hline N=14 & Cohort 2, Year 2 \\
\hline & High & Med & Low & $\begin{array}{l}\text { No } \\
\text { Rating }\end{array}$ \\
\hline Source & & & & \\
Control & 5 & 3 & 0 & 4 \\
\hline UNIX & 4 & 8 & 2 & \\
\hline HTML/CSS & 8 & 6 & 0 & \\
\hline Graphics & 6 & 8 & 0 & \\
\hline PHP & 8 & 4 & 2 & \\
\hline MYSQL & 6 & 6 & 2 & \\
\hline EXCEL & 14 & 0 & 0 & \\
\hline Obj. Orient. & 7 & 7 & 0 & \\
Prog. & & & & \\
\hline
\end{tabular}

Fig. 5. Advanced Skill Level

Advanced Skill Level. Technical (IT) Skills

During the apprentices' second year these skills are developed further through individual and group projects that involve planning, execution, problem solving, reporting and presentation. As noted above, Advanced Apprentices were required to attend classes but were allowed more flexibility in hours since group projects are the main focus of the second year and successful completion of projects is the goal.

During the Summer session all Advanced apprentices participated actively in complex projects that required the use of IT skills well beyond the basic level. As in the previous year advanced apprentices were divided into four teams to work with mentors to design and produce interactive websites for clients in the community. At the end of the summer session each group prepared and presented a presentation to the sponsors of the project. Successful completion and acceptance by clients is clear evidence of the attainment of IT skills.

In addition to continuing informal assessment and feedback to apprentices, mentors rated the Advanced Apprentices (Cohort 2) at the end of their second year on a scale of 1-5 on a range of IT skills. For this rating the criteria were more stringent than on the rating after the first year. Those given a rating of 4-5 were deemed expert and able to teach the skill to others. A rating of 3 indicated successful use of the skill in projects assigned and completed. Although a rating of 1 was possible, none of the apprentices received this rating, indicating that all apprentices had developed at least a minimum level of proficiency in every skill.

The results of the assessment by mentors who have been actively engaged with apprentices indicates that, with very few exceptions, all apprentices who persisted in the program are able to use the IT skills listed above at an expert or practical level in any environment where these skills are required.

GOAL 4: To gather evidence of the effectiveness of this structure for increasing participation of traditionally underrepresented demographic groups in ITintensive workplaces. 
The Apprenticeship program, as it has developed over three years, enables students of diverse backgrounds to gain IT proficiency. We have shown that students of diverse racial and ethnic backgrounds have gained proficiency in a wide range of IT skills. $\mathrm{T}$ he percentage of underrepresented groups remains high among the apprentices who persist through the entire 26 -week program. In addition, many students who have participated in the program expect to have IT-related careers and thus will take their places in IT-intensive workplaces as they move into the adult workforce. An interesting and unusual aspect of the population of apprentices in the program is the high percentage of African American females. We believe that interaction between students of diverse races, ethnicities and genders in a learning environment where respect for all students, as well as mentors and instructors, is the norm and is expected and required has been an important aspect of the program.

The results of the assessment by mentors who have been actively engaged with apprentices indicates that, with very few exceptions, all apprentices who persisted in the program are able to use the IT skills listed above at an expert or practical level in any environment where these skills are required.

\section{Summary}

The first two of three groups (cohorts) of Apprentices have now completed the 2-year Apprenticeship program and a third group is continuing through the current year. Since enrollment in the program began in late 2005 a total of 124 students have been admitted into the program; 86 have completed the first year of the program and 29 have completed the full 26-week program. Approximate 20 additional apprentices are expected to complete the full program in Summer 2009.

For three successive years the project has been notably successful in recruiting a diverse group of students and in maintaining diversity in the groups who have persisted through the full program. The program has also been successful in maintaining apprentices' interest in STEM and STEM-related careers. The program, now entering its final year, is expected to continue the curriculum and other practices that have been tested and found to be effective over the past three years. The curriculum, lesson plans and resources are being made available for others interested in developing a similar program at (http://shodor.org/succeed/curriculum/apprenticeship/). 